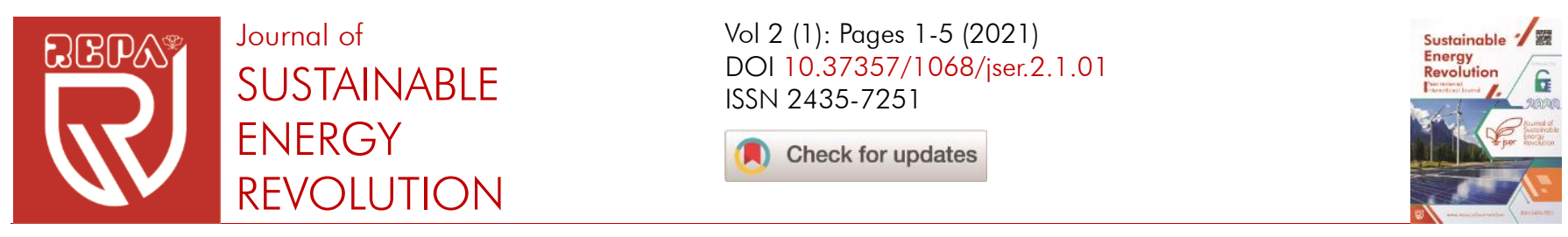

\title{
Smart and sustainable building appraisal
}

Mir Sayed Shah Danish ${ }^{1}$, Tomonobu Senjyu², Masooma Nazari³, Hameedullah Zaheb ${ }^{2}$, Thabit Salim Nassor ${ }^{4}$, Sayed Mir Shah Danish ${ }^{5}$ and Hedayatullah Karimy ${ }^{6}$

${ }^{1}$ Strategic Research Project Center, University of the Ryukyus, 1 Senbaru 9030213, Japan

${ }^{2}$ Department of Electrical and Electronics Engineering, Faculty of Engineering, University of the Ryukyus, Okinawa 903-0213, Japan

${ }^{3}$ Department of Electrical and Electronics Engineering, Graduate School of Engineering, University of Alberta, 85 Ave. Edmonton, Alberta T6G 2R3, Canada

${ }^{4}$ Department of Mechanical and Automotive Engineering, Karume Institute of Science and Technology (KIST), Mbweni Road, Zanzibar, Tanzania

${ }^{5}$ Department of Electrical Engineering, Technical Teachers Training Academy (TTTA), Chihl Sutton, Kabul, Afghanistan

${ }^{6}$ Department of Energy Engineering, Faculty of Engineering, Kabul University, Kabul 1006, Afghanistan

\section{Article}

Open Access

Published

Keywords

- Energy conservation

- Energy efficiency

- Sustainable building

- Smart city

- Value chain

\section{ABSTRACT}

In general terms, energy efficiency and conservation appraisal aspire to deliver an insatiable energy demand with less energy within the most significant amount of conservation and environmental benefits at the lowest possible price. Sustainable planning and design rely on a series of multi-disciplines: technical, technological, social, political, environmental, ecological, economic, institutional, and global restrictions that abstruse viable decision-making. Recent reports indicate that the residential building sector consumes $40 \%$ of the total energy and emits $30 \%$ of greenhouse gas (GHGs) worldwide. Thus accordingly, energy consumption in buildings is estimated at one-third of total primary energy resources. Therefore, proper modeling and optimization of a sustainable building in terms of energy efficiency and saving become a matter of focus. This paper explores an emerging picture of influential factors in the context of hands-on roadmap for energyefficient and smart city planners, practitioners, scholars, and researchers. This study reviews the main points and proposes a framework in detail in the upcoming studies. Meanwhile, another objective of this paper was to introduce the most crucial indicators of energy-efficient building planning, design, and optimization to draw an exhaustive roadmap in compliance with resiliency, sustainability, and efficiency criteria throughout the lifecycle of a sustainable building.

Received: July 20, 2021; Revised: August 11, 2021; Accepted: August 12, 2021; Published: August 20, 2021 (C)2021 REPA. All rights reserved.

\section{Introduction}

Energy as an indispensable factor for socio-economic development has remained an interesting topic for many researchers around the globe. An increasing day by day energy demand in the world pursues scholars and researchers to pave the way for positive change and innovative options. Meanwhile, increasing demand for energy intimidates the globe for an uncontrollable situation for a long period, which unbelievably will affect routine life [1]. Globe development trends knotting with greenhouse gases emissions and environmental constraints. Among energy utilities in a smart city, buildings consume a significant amount of energy that can be different based on energy consumption culture from country to country. According to reports [2-5], buildings consume $40 \%$ of the total energy and emit 30\% of greenhouse gas (GHGs) worldwide. Ecumenically, attention is paid to switching to renewable energy sources and considering the sustainability dimensions from technical and technological innovation to climate change mitigation, cost reduction, and fossil fuel independence [6].

Prabha Kunder [7], besides the requirement and challenges of sustainability of an electric power system, pointed out the role of new technology. The author claims that the energy industry shifts from a monopolistic to a competitive structure in the 21st century and requires balancing economic growth and preserving the natural environment [7]. While, this shifting is due to new technologies directly undergoing technical, technological, economic, social, environmental, institutional, and political impacts within the territories around the globe. Power systems normal operation avoiding potential risk of blackout is part of sustainability measures. However, power systems are associated with possible blackouts, which can be occurred even in any system, e.g., Tokyo blackout on July 23, 1987; Amalgamated Kingdom, Sweden, Canada, Denmark, Italy, and the Cumulated States blackouts in 2003 [8]. Economic and competitive electricity markets push the utilities to operate power systems with maximum generation capacity close to the collapse point, leading to high risks of failure and blackouts [9]. Therefore, sustainable operation recommends a broader perspective, balancing technical, technological, economic, environmental, institutional, social appraisals for optimum benefits for long-run sustainability [10].

For the European case, the green mortgage is proposed that fund on energy efficiency, means lower energy bills and higher property value [11]. For achieving the ambition binding legislation related to energy efficiency, 
different stakeholders are involved in minimizing risks and ensuring mutual trust among investors, granters, guarantors, and beneficiaries (homeowners) [11,12]. This target for Europe is predicted from $27 \%$ to $30 \%$ stimulates savings and $40 \%$ within the same time frame by millions of extra residential and business buildings renovation by 2030 [11].

However, a large and growing body of literature has emphasized improving building energy efficiency within constrained greenhouse gas emissions. The second pillar of a sustainable building (cost-effectiveness of an energy system by management and business practices) that directly influences the sustainability pentagon remains limited and just briefly pointed out in the literature. In comparison, it is noteworthily covered in this study in a systematic approaches' manner.

In an emerging consensus among practitioners and scholars $[13,14]$ in the 21th-century, energy industry challenges concerning efficiency and conservation are listed as follows:

- Produce, transmit and utilize energy in an environmentally friendly manner;

- Reduce overall costs by enhancement of generation and operation efficiencies; and

- Diminish overall costs by the smooth implementation of management and business practices.

However, feasible solutions cannot be suggested unless all aspects of energy efficiency and conservation (codes and standards [15]) are thoroughly analyzed. The analysis process involves a thorough profound investigation of the various factors (technical, economic, social, environmental, and institutional). Some causes of these factors that can play an important part in optimizing building sustainability are explained, followed by effects exertion of these causes.

\section{Energy efficiency and conservation}

Energy conservation concerns reducing energy consumption that causes conservation in resource and cost and boasts climate change combat. This endeavor can be erected by habitual action of turning off additional lights and using energy-efficient appliances to elaborate sectorial energy conservation plans (manufacturer, building, agriculture, etc. sectors) [16-18].

In principle, energy efficiency is the amount of useful output generated from using one unit of energy input, measured by various indicators [19] that can be improved by energy conservation phenomenon. Eventually, efficiency came to attention by the end of the $19^{\text {th }}$ century, along with global industrialization and commercial generation and trade of energy [20].

Apart from technical efficiency (supply, demand, and operation efficiencies), authors in [21] discussed the urgency of economic efficiency align with marginal safety and future projection margin (planning). Economic efficiency measures are taking to meet efficiency targets, tiers categorizing technical, economic, realizable, and realistic efficiency potentials are essential [19]. In an overall outlook, renewable energy deployment and management encountered subtle barriers in terms of [22]:

- Economic efficiency of renewable energy systems

- Politics and legal issues

- Investment and financing

- International trade and marketing

- Standardization and interoperability

\section{Building sustainability}

A sustainable building in a smart city pursues five pillars of sustainability within three main principles $[1,23]$. These pillars introduce technical, economic, environmental, social, and institutional sustainability that comprise many components and processes to attain sustainability goals [22]. Thus, sustainable planning and design rely on a series of multi-disciplines: technical, technological, social, political, environmental, ecological, economic, institutional, and global restrictions that abstruse viable decision-making [24].

According to the literature, the most important criteria to attain sustainability goals are accessibility, affordability, disparity, safety, use efficiency, supply and production efficiency, cost-effectiveness, and environmental impacts on air, water, and soil quality [20]. For example, authors in [1] listed the main factors linked to building sustainability as: "health and hygiene, indoor air quality, noise and acoustics, environment, safety, controllability, serviceability, adaptability, living quality, energy efficiency, use of renewable energy technologies, water conservation, automation, reuse options, waste management, cultural character, building economics, security, and nature and heritage conservation." Whereas $97 \%$ of cities with more than 100,000 inhabitants in low and middle-income countries suffering from low-quality air that contribute to different diseases [25].

The latest literature [26-29] sorted the main challenges of sustainable building planning and implementation: multifaceted design, affordability, marketability, appropriate-competitive design, resource efficiency, energy efficiency, durability, comfort, and healthy lifestyle.

An overall picture of building energy cost resulting from various segments of design, implementation, and operation is lifecycle cost from an economic perspective [30]. From code and standard point views, establishing the minimum level of energy efficiency for new buildings and renovations to existing buildings must demonstrate $18 \%$ and $14 \%$ improvement, respectively. These figures can be varied depending on the methods and types of codes and standards [31,32]. In brief, this study addresses a better assessment of barriers to adopting energy-efficient 
measures in the buildings within a structured approach in identifying and providing solutions to these barriers. More specifically:

- What are the most typical barriers to adopting energy-efficient measures in buildings, considering buildings characteristics, age, and so on?

- How to classify these barriers to manage and address them easily?

- Which research studies and industry practices are exposed so far to the identified challenges to utilize these lessons learned?

- How to unify, and order these challenges into a structured framework for better modeling and solutions?

\section{Findings and future work}

However, the literature covers a wide range of different approaches to analyzing a sustainable building; this study put forward building sustainability appraisal through lifecycle and value chain analyses, which is concerned with the primary objective of efficiencies, conservation, and sustainability. Value chain management concerning a smart city energy infrastructure can provide multilateral national and regional aspirations to enable a sustainablesmart energy city. However, the standard process presents a typical model that can be different from case to case. The thesis line of smart city, energy efficiency and conservation types of available and projected potentials is a compulsory part of this model.

In the context of an existing building, an integration process can examine modeling options with various feasible changes; remodeling results show improvement in building design, energy-saving, alternative energy source integration possibility, and reducing in capital and operation cost of energy.

Since renewable energy and efficiency are the hope for the future of energy transition, overall recommendation authors in [33] listed important points as energy policy and regulation reform, well-governance of resources and technologies, ingenious investment, research development, and being along with time to be considered. Also, this study sums up with six phases for green building planning and design, such as developing a business model, planning the project, interpreting the scopes and making viable, conceiving and managing constraints, shaping the project smoothly, and successfully handing over the project [33]. For proper planning and design, identification and development of indicators are known exigence. Indicators are frequently used in quantitative and qualitative measures to evaluate the current status and provide future outlook with specific targets $[34,35]$.

\section{Conclusion}

A great deal of sustainable building modeling through optimized efficiency and energy conservation involves understanding and suggesting viable solutions to real-world challenges. The proposed concept of value chain management and lifecycle analysis in terms of smart cities appraisal delivers a systematic process to explore all influential factors exhaustively to the city energy system. This tool assembles challenges in a hierarchy of uncertainties within a viable risk plan priorities from initiation to operation phases. That contributes to planners and operators having a solid understanding of the system for current and future endeavors. Also, the value chain analysis facilitates the proper identification of tools and techniques to fit the optimization objectives. This study adds implication value for future practice as multilateral planning and design reference for students, researchers, scholars, and practitioners in the context of sustainable building and smart cities. The authors will keep continuing to complete the proposed framework with a detailed procedures paradigm within management, engineering, and business domains in a synergistic manner in the future.

\section{References}

[1] Danish MSS, Senjyu T, Ibrahimi AM, Ahmadi M, Howlader AM (2019) "A managed framework for energy-efficient building" Journal of Building Engineering (vol. 21, pp. 120128) https://doi.org/10.1016/j.jobe.2018.10.013

[2] Brenna M, Falvo MC, Foiadelli F, Martirano L, Poli D (2012) "Sustainable Energy Microsystem (SEM): preliminary energy analysis" 2012 IEEE PES Innovative Smart Grid Technologies (ISGT) Washington, DC, USA, IEEE - pp. 1-6. https://doi.org/10.1109/ISGT.2012.6175735 (http://ieeexplore.ieee.org/document/6175735/) Accessed: 3 February 2019

[3] Bourdeau M, Zhai X qiang, Nefzaoui E, Guo X, Chatellier P (2019) "Modeling and forecasting building energy consumption: A review of data-driven techniques" Sustainable Cities and Society (vol. 48, pp. 101533) https://doi.org/10.1016/j.scs.2019.101533

[4] Nematchoua MK, Yvon A, Roy SEJ, Ralijaona CG, Mamiharijaona R, et al. (2019) "A review on energy consumption in the residential and commercial buildings located in tropical regions of Indian Ocean: A case of Madagascar island" Journal of Energy Storage (vol. 24, pp. 100748) https://doi.org/10.1016/j.est.2019.04.022

[5] Kräuchi P, Dahinden C, Jurt D, Wouters V, Menti U-P, et al. (2017) "Electricity consumption of building automation" Energy Procedia (vol. 122, pp. 295-300) https://doi.org/10.1016/j.egypro.2017.07.325

[6] Kostyk T, Andrews CJ, Herkert J, Miller C (2011) "Energy and society: challenges ahead" 2011 IEEE International Symposium on Technology and Society (ISTAS) pp. 1-1. https://doi.org/10.1109/ISTAS.2011.7160603

[7] Kundur P (2004) "Sustainable electric power systems in the 21st century: requirements, challenges and the role of new technologies" IEEE Power Engineering Society General Meeting, 2004. Denver, CO, USA, IEEE, vol. 2 - pp. 22982299. https://doi.org/10.1109/PES.2004.1373295 (http://ieeexplore.ieee.org/document/1373295/) Accessed: 3 February 2019

[8] Danish MSS, Senjyu T, Danish SMS, Sabory NR, K N, et al. (2019) "A Recap of Voltage Stability Indices in the Past 
Three Decades" Energies (vol. 12, no. 8, pp. 1544) https://doi.org/10.3390/en12081544

[9] Danish MSS, Yona A, Senjyu T (2015) "A Review of Voltage Stability Assessment Techniques with an Improved Voltage Stability Indicator" International Journal of Emerging Electric Power Systems (vol. 16, no. 2, pp. 107-115) https://doi.org/10.1515/ijeeps-2014-0167

[10] Danish MSS, Senjyu T, Zaheb H, Sabory NR, Ibrahimi AM, et al. (2019) "A novel transdisciplinary paradigm for municipal solid waste to energy" Journal of Cleaner Production (vol. 233, pp. 880-892)

[11] O’Neill-Carrillo E, Irizarry-Rivera AA, Colucci-Rios JA, Perez-Lugo M, Ortiz-Garcia C (2008) "Sustainable Energy: Balancing the Economic, Environmental and Social Dimensions of Energy" 2008 IEEE Energy 2030 Conference Atlanta, GA, USA, IEEE - pp. 1-7. https://doi.org/10.1109/ENERGY.2008.4781010 (http://ieeexplore.ieee.org/document/4781010/) Accessed: 21 July 2019

[12] Putting energy efficiency first: consuming better, getting cleaner (2019) European Commission (http://europa.eu/rapid/press-release_MEM0-16-3986_en.htm) Accessed: 21 July 2019

[13] Akadiri PO, Chinyio EA, Olomolaiye PO (2012) "Design of A Sustainable Building: A Conceptual Framework for Implementing Sustainability in the Building Sector" Buildings (vol. 2, no. 2, pp. 126-152) https://doi.org/10.3390/buildings 2020126

[14] Dahunsi FM (2013) "Conceptual framework for sustainable energy development in Africa" 2013 IEEE International Conference on Emerging \& Sustainable Technologies for Power \& ICT in a Developing Society (NIGERCON) Owerri, Nigeria, IEEE - pp. 238-241. https://doi.org/10.1109/NIGERCON.2013.6715661 (http://ieeexplore.ieee.org/document/6715661/) Accessed: 21 July 2019

[15] Gutiérrez Trashorras AJ, González-Caballín Sánchez JM, Álvarez Álvarez E, Paredes Sánchez JP (2015) “Certification of Energy Efficiency in New Buildings: A Comparison Among the Different Climatic Zones of Spain" IEEE Transactions on Industry Applications (vol. 51, no. 4, pp. 27262731) https://doi.org/10.1109/TIA.2015.2394374

[16] Zheng S, Lam C-M, Hsu S-C, Ren J (2018) "Evaluating efficiency of energy conservation measures in energy service companies in China" Energy Policy (vol. 122, pp. 580-591) https://doi.org/10.1016/j.enpol.2018.08.011

[17] Farrow K, Grolleau G, Mzoughi N (2018) "Less is more in energy conservation and efficiency messaging" Energy Policy (vol. 122, pp. 1-6) https://doi.org/10.1016/j.enpol.2018.07.007

[18] Qian D, Li Y, Niu F, O'Neill Z (2019) "Nationwide savings analysis of energy conservation measures in buildings" Energy Conversion and Management (vol. 188, pp. 1-18) https://doi.org/10.1016/j.enconman.2019.03.035

[19] Fedorova E, Pongrácz E (2019) "Cumulative social effect assessment framework to evaluate the accumulation of social sustainability benefits of regional bioenergy value chains" Renewable Energy (vol. 131, pp. 1073-1088) https://doi.org/10.1016/j.renene.2018.07.070

[20] Danish MSS, Senjyu T, Sabory NR, Danish SMS, Ludin GA, et al. (2017) “Afghanistan's aspirations for energy independence: Water resources and hydropower energy" Renewable Energy (vol. 113, pp. 1276-1287) https://doi.org/10.1016/j.renene.2017.06.090

[21] Danish MSS, Matayoshi H, Howlader HOR, Chakraborty S, Mandal P, et al. (2019) "Microgrid Planning and Design: Resilience to Sustainability" Bangkok, Thailand, IEEE -

[22] Danish MSS, Sabory NR, Ershad AM, Danish SMS, Yona A, et al. (2017) "Sustainable Architecture and Urban Planning trough Exploitation of Renewable Energy" International Journal of Sustainable and Green Energy (vol. 6, no. 3, pp. 17) https://doi.org/10.11648/j.ijrse.s.2017060301.11

[23] Kim J-J, Rigdon B (1998) "Sustainable Architecture Module: Introduction to Sustainable Design" National Pollution Prevention Center for Higher Education (pp. 28)

[24] Danish MSS, Senjyu T, Zaheb H, Sabory NR, Ibrahimi AM, et al. (2019) "A Novel Transdisciplinary Paradigm for Solid Waste to Sustainable Energy" Journal of Cleaner Production (vol. (under review), )

[25] Danish MSS, Zaheb H, Sabory NR, Karimy H, Faiq AB, et al. (2019) "The Road Ahead for Municipal Solid Waste Management in the 21st Century: A Novel-standardized Simulated Paradigm" The 3rd International Conference on Energy and Environmental Science 2019 (ICEES 2019) Seoul, South Korea, IOP Conference Series: Earth and Environmental Science (EES), vol. (in press) -

[26] Jensen PA, Maslesa E, Berg JB, Thuesen C (2018) "10 questions concerning sustainable building renovation" Building and Environment (vol. 143, pp. 130-137) https://doi.org/10.1016/j.buildenv.2018.06.051

[27] Shealy T (2016) "Do Sustainable Buildings Inspire More Sustainable Buildings?" Procedia Engineering (vol. 145, pp. 412-419) https://doi.org/10.1016/j.proeng.2016.04.008

[28] Oduyemi O, Okoroh M (2016) "Building performance modelling for sustainable building design" International Journal of Sustainable Built Environment (vol. 5, no. 2, pp. 461-469) https://doi.org/10.1016/j.ijsbe.2016.05.004

[29] Díaz López C, Carpio M, Martín-Morales M, Zamorano M (2019) "A comparative analysis of sustainable building assessment methods" Sustainable Cities and Society (vol. 49, pp. 101611) https://doi.org/10.1016/j.scs.2019.101611

[30] Danish MSS, Yona A, Senjyu T (2014) "Pre-design and life cycle cost analysis of a hybrid power system for rural and remote communities in Afghanistan" The Journal of Engineering-IET (vol. 2014, no. 8, pp. 438-444) https://doi.org/10.1049/joe.2014.0172

[31] Azhar S, Carlton WA, Olsen D, Ahmad I (2011) "Building information modeling for sustainable design and LEED $®$ rating analysis" Automation in Construction (vol. 20, no. 2, pp. 217-224) https://doi.org/10.1016/j.autcon.2010.09.019

[32] Humbert S, Abeck H, Bali N, Horvath A (n.d.) "Leadership in Energy and Environmental Design (LEED) - A critical evaluation by LCA and recommendations for improvement" (pp. 18)

[33] Danish MSS, Senjyu T (2019) "Green Building Efficiency and Sustainability Indicators" Green Building Management and Smart Automation, 1st ed. IGI Global, vol. (In press) pp. 1-20. 
[34] Popovic T, Barbosa-Póvoa A, Kraslawski A, Carvalho A (2018) "Quantitative indicators for social sustainability assessment of supply chains" Journal of Cleaner Production (vol. 180, pp. 748-768) https://doi.org/10.1016/j.jclepro.2018.01.142
[35] Tripathi V (2016) "A literature review of quantitative indicators to measure the quality of labor and delivery care" International Journal of Gynecology \& Obstetrics (vol. 132, no. 2, $\mathrm{pp}$ 139-145) 